\title{
A Simulation Study of Implementing Strategies for Reducing Convection Providing Natural Ventilation for Interior Spaces in Public Buildings
}

\author{
Qubad Sabah Haseeb and Anas Attellah Ali Shoshan \\ College of Engineering, University of Kirkuk, Kirkuk, Iraq
}

\begin{abstract}
The strategies of reducing convection through solar breakers and natural ventilation are factors influencing the design and construction of buildings. The main reason is that the movement of air in the interior spaces of any building generates a powerful impact on the thermal comfort of its occupants. Recently, the field of reducing the convection and its techniques have considerable attention in civil architecture design. It represents one of the most critical elements in the process of air conditioning with various climatic and environmental factors. Therefore, the methods and techniques have been developed depending on the climatic nature of each region of the world. This study examines the most important mechanisms and advanced techniques used in the field of reducing convection and natural ventilation. The primary purpose of applying this study is to provide an appropriate health environment in the interior spaces. Additionally, to achieving a sustainable environment and avoid wasting it according to the datum conditions of the proper climatic environment. That corresponds to the standards of modern buildings which are in turn the most important goals of designers in the architectural area. The main challenges are to preserve natural resources and minimize air pollution caused by the excessive use of machinery and equipment.
\end{abstract}

Key words: Natural ventilation, convection, sustainability, environment, modern buildings, air pollution

\section{INTRODUCTION}

The Middle East Region has been considered the hot spots during the Summer season. Iraq is one of those hot and dry climates and it is necessary to obtain appropriate solutions to get rid of heat in the Summer season. Over the past decades the architectural design in the construction of buildings in the Arab countries (Iraq in particular) was influenced by social and environmental nature. The old buildings used traditional treatments architecture by using the interior courtyard significantly. The reason for this is to create a comfortable atmosphere environmentally. Additionally, to provide ventilation and convection, natural lighting and saving a pleasant atmosphere within the interior spaces of the buildings. This style was taken into consideration to design of the residential role and it emerges from ancient times until the late 1990's.

However, modern buildings usually use advanced techniques to take the benefit of moving the air and providing shadows within the spaces of buildings in contemporary architecture. This can be achieved in accordance with the building itself and the climatic nature of its area. Recently, new methods and systems have emerged in the field of heat treatment which characterizes the atmosphere of the study area. The natural air and other natural energy sources are exploited by employing them according to the Sun and wind mainly. Then, mechanical devices can be adopted as a secondary option.

Therefore, this research interests in the field of modern technologies. It aims to reduce the convection to provide natural ventilation for the internal spaces. It is relied on renewable energy because of its importance in the public arena. Consequently, minimize the worsening health problems caused by pollution of the environment and high consumption of energy and natural resources of each region.

Problem statement: Recently, much attention has been paid to solve the problem of reducing convection and providing natural ventilation in the urban environment. It is seen that the implementing of mechanical methods causes a large waste of energy through the need to generate electricity. Thus, it causes serious health problems, environmental pollution and exhaustion of natural resources. Accordingly, it is necessary to evaluate this problem and make efforts to find solutions and appropriate recommendations.

Corresponding Author: Qubad Sabah Haseeb, College of Engineering, University of Kirkuk, Kirkuk, Iraq 
Significance of study: The main goal of this research is to study the essential techniques that contribute to providing the appropriate thermal and ventilation environment in the interior spaces in the urban environment. We took the benefit from the traditional architecture and design solution to be suitable for the climatic environment of the region without the depletion of energy and waste of natural resources.

\section{MATERIALS AND METHODS}

\section{Theoretical study}

Defecation of ventilation: In general, the ventilation refers to breathing in oxygen and breathing out carbon dioxide. In other words, the movement of air between the environment and the lungs via. inhalation and exhalation. Ventilation moves outdoor air into a building or a room and distributes the air within the building or (the rooms). The general purpose of ventilation in buildings is to provide pure air-breathing by both diluting the pollutants originating in the building and removing the pollutants (Waziri, 2007). Basically, ventilation is categorized into natural ventilation and mechanical ventilation. We now briefly describe both mechanisms as follows.

Natural ventilation: It is applicable to all types of ventilation in which the movement of air inside buildings by wind power or air temperature difference. The air traffic can be caused by one or both former workers and depending on external weather conditions and the nature and location of the building. It is noted that the rate of natural ventilation is not constant because it depends on the wind speed and differences in air temperature changes over time. Therefore, achieving proper ventilation of the building is the essential factors to overcome the concentration of pollutants. However, it is necessary to direct the openings of the building to the direction of the prevailing winds in each area which can be performed by taking care to have more than one hole in each room (Atkinson et al., 2009).

Mechanical ventilation: It is well known that mechanical fans drive mechanical ventilation. Fans can either be installed directly in windows or walls. Additionally, they can be installed in air ducts for supplying air into or exhausting air from a room. In the literature, the type of mechanical ventilation depends on the climate. For example, in warm and humid climates, infiltration may need to be minimized or prevented to reduce interstitial condensation. It can be implemented in warm, moist air from inside a building penetrates a wall, roof or floor. In these cases, a positive pressure mechanical ventilation system is often used. Conversely, in the cold climates, exfiltration needs to be prevented in order to reduce interstitial condensation. In consequence, negative pressure ventilation must be applied. For a room with locally generated pollutants such as a bathroom, toilet or kitchen, the negative pressure system is often used (Dragan, 2000).

In a positive pressure system, the room is in positive pressure and the room air is leaked out through envelope leakages or other openings. Whereas in a negative pressure system, the room is in negative pressure and the room air is compensated by "sucking" air from outside. A balanced mechanical ventilation system refers to the system where air supplies and exhausts have been tested and adjusted to meet design specifications. The room pressure may be maintained at either slightly positive or negative pressure which is achieved by using unequal supply or exhaust ventilation rates. For example, a slight negative room pressure is achieved by exhausting $10 \%$ more air than the amount in a cold climate to minimize the possibility of interstitial condensation. In an airborne precaution room for infection control, a minimum negative pressure of $2.5 \mathrm{~Pa}$ is often maintained relative to the corridor (Dragan, 2000; Auf, 1997).

Functions of natural ventilation: Natural ventilation and air movement achieve three purposes: providing fresh and healthy air, cooling or heating of buildings and refrigeration of residents. Firstly, cooling or heating the buildings from the inside with load currents. This comes when there is a difference in temperature between the inside and outside until the building is cooled from the inside (the temperature outside should be cooler than inside and vice versa). This difference in temperature depends on how the temperature changes during the day (structural cooling is the heat obtained from the outside and heat generated at home or the combination of all these factors).

For the second function, refrigeration of residents in specific conditions by cooling the body, removing sweat and moisture from the human body. Thus, the ventilation increases the process of heat loss by convection currents due to rapid air movement in the presence of air currents. If we do not feel proper ventilation at the body level, the cold and refreshed feeling will not be achieved the desired purpose. The sense of cold and recovery do not come as a result of the cold body but it comes as a result of the 

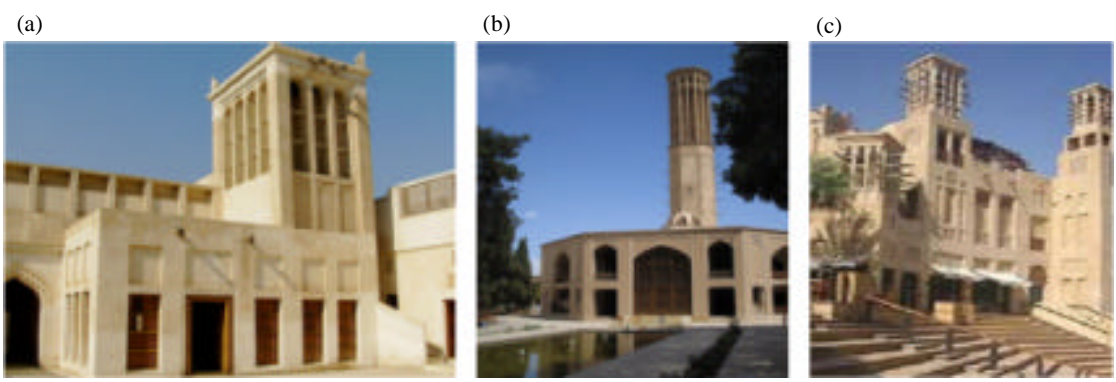

Fig. 1: a-c) The use of wind catcher in different forms in the Gulf States

passage of air currents fast enough to evaporate sweat and reduce the temperature of the body gradually leading to a sense of cold.

Applications of natural ventilation systems: As we mentioned earlier there are several applications of natural ventilation systems in contemporary architecture. It depends on the nature of the building and its function, geographical location, climate environment and architectural design. So, we can review the most important applications and its mechanism in order to achieve natural ventilation as follow:

Wind tower system (wind catcher): It is a tower with air ports above the facades of the buildings to pull cold air down to enter the interior rooms of the house or buildings (Fig. 1). The external air movement from the top creates a "pressure differentials" that helps more to pull the air from the inside. Therefore, its presence with "Mashrabiya" ensure the constant renewal of the cabin air. Wind tower (or wind catcher) provides natural ventilation by taking clean air that is free from dust and other impurities from the upper layers of outer space and make it flow through the internal areas. Regardless of the general direction of the building and its relation to the direction of the wind it helps to increase the speed of the air inside the building. The size of the wind catcher depends on the temperature of the air outside in the case the temperature in the entrance of windcatcher is low. Therefore, the horizontal partition must be large. Nonetheless, if the temperature is higher than the maximum thermal comfort then the horizontal study must be small. Additionally, it should be provided in such a way that the air is cooled through inside by using a wet tatami or wet plates of charcoal placed between two plates of metal mesh. Furthermore, the flowing air can be directed over a water element like Salsabil or Fountain in order to increase its moisture level (MLtd., 2019).
Modern technologies of wind catcher system: Recently, the wind catcher system has evolved significantly and emerged with new technologies such as Monodraught wind catcher. Since, 2000, the kind of wind catcher considered an extension of wind catchers which has spread in the Middle East Region. This system made a significant development of air ducts that operate on the principle of thermal propulsion with a chimney system. It has been proved that the wind catcher is the most effective way to provide optimal natural ventilation. It is implemented even commercial buildings in Europe including all British companies (FP., 2019). Monodraught wind catcher has shown its superiority on other natural ventilation systems because it does not depend on wind direction. Furthermore, the types of wind catcher vents with guided blades and always one-way catch the prevailing wind. Moreover, the direction of the air movement is changed to a $90^{\circ}$ angle to bring the air into the building's vacuum where the valves are open. Due to the variation in temperature between inside and outside the building it affects air density and gives more pressure on internal and external air blocks. Then, the warm air rises at an angle of $90^{\circ}$ to get out and spread in the outside atmosphere. As shown in Fig. 2, the system provides natural ventilation at night and day during the Summer months according to the mechanism.

Alternate discharge in high tower buildings: This method is one of the best ways to vent the spaces in tower buildings where the air is provided from the lower areas to drive through the alternating openings overlooking the inner courtyard. One of the most important towers that depend on this technique in ventilation is Regional Commercial Bank Tower in Frankfurt, German (which was designed by architect Norman Foster) (Riain et al., 1999). It consists of fifty-three floors and considered the first office tower in the world in addition to being as the tallest building in Europe. 


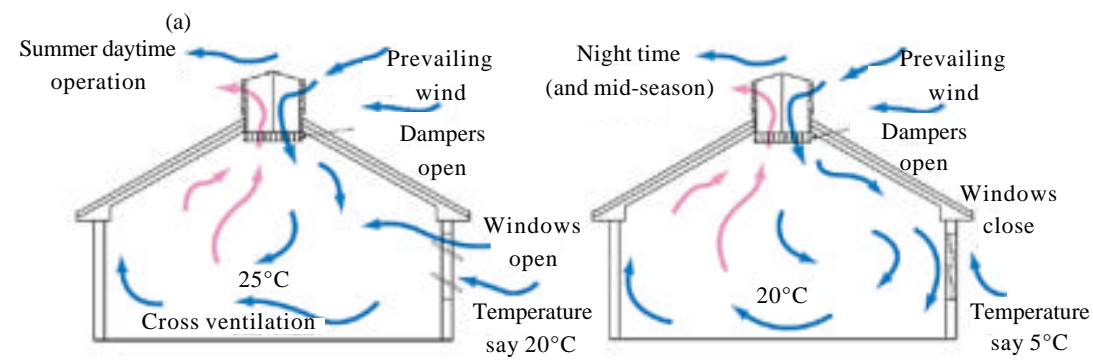

(b)

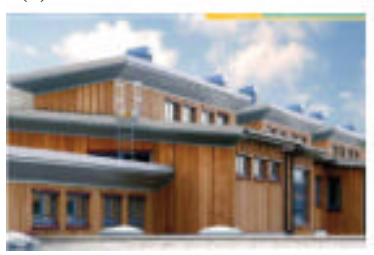

(c)

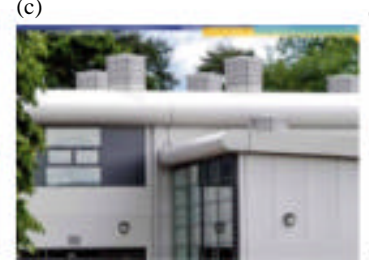

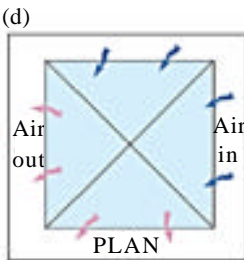

Fig. 2: a-d) Demonstrates the process of ventilation during the day for a building
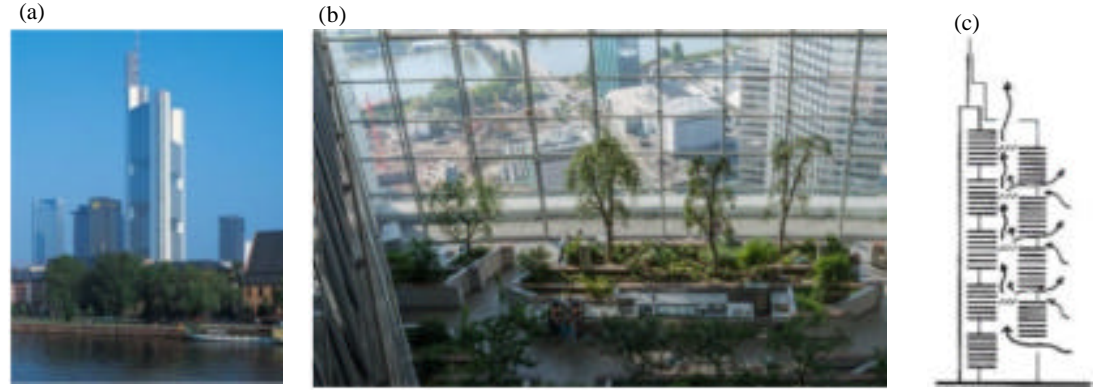

Fig. 3: a-c) Natural ventilation at the commercial bank regional management tower in Frankfurt, Germany
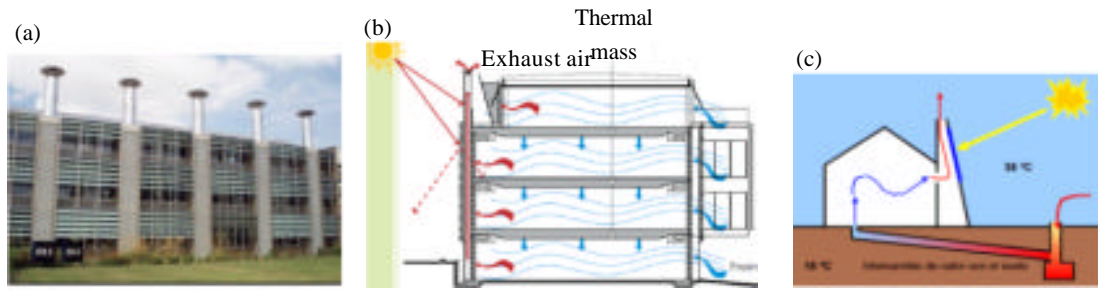

Fig. 4: a-c) The solar chimney mechanism at the Greystone and Watford buildings in the United Kingdom and the Victoria Parks building in Sydney

The purpose of this project is to explore the nature of the high office building. According to this trend, we study the new ideas developed for its relationship to the environment. The basic idea of this concept relies on the natural systems of lighting and ventilation. All offices are flooded with daylight and have windows that can be opened, allowing employees to control the surrounding work environment.

Nevertheless, the result of this system in terms of energy consumption is equivalent to half of the levels in the traditional office towers and environmentally. Additionally, the gardens help flow daylight and fresh air into the central courtyard and act as a "chimney" for the natural ventilation of offices on the inside. Depending on the direction of each garden, plants were selected from one of the following three regions: North America, Asia or the Mediterranean Region (Fig. 3).

Solar chimney system: As shown in Fig. 4, solar chimney system (so-called a thermal chimney) is a way to improve 

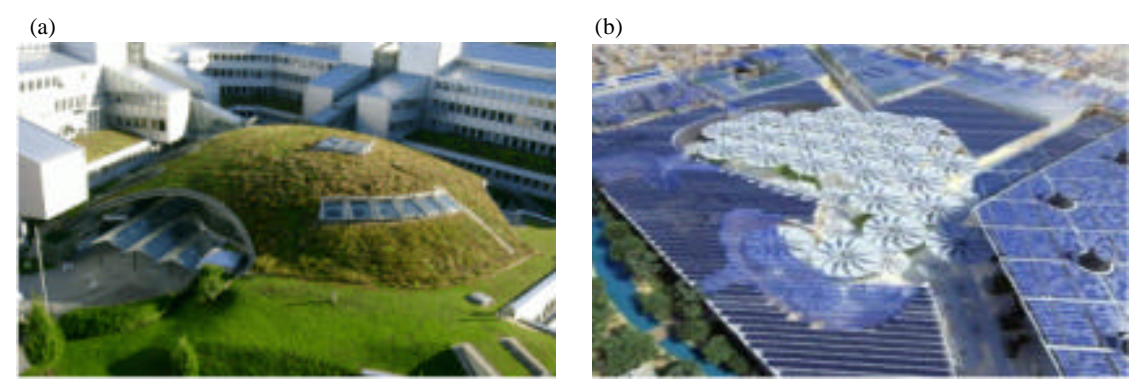

Fig. 5: a, b) The models of moving surfaces and green surfaces to provide natural ventilation and temperate atmosphere

natural ventilation in buildings using convection of heated air from inert solar energy. It is considered as a vertical pathway that uses solar energy to enhance the natural ventilation of the building. The solar chimney has several types and forms where the simplest one is that it is painted with black to absorb the largest amount of solar radiation. During the day with high temperatures, the hot air stream inside the chimney rises to the top and the cold air enters from the bottom (Al-Hamdi, 1999). The elements of the solar chimney consist of the following:

- Solar collector area: located in the upper part of the chimney used to guide

- Main ventilation slot: location and elevation are two crucial factors

- Air inlet and outlet openings

Surfaces and cooling of building causes: The surfaces have a significant role in providing natural ventilation. It has handled in modern ways (such as covering the spaces, the walls with surfaces and moving elements, the possibility of opening and closing automatically) in order to discharge the air from the top of the vacuum and grab it from the bottom to create a stream of air in the inner space (Atwa et al., 2018).

The cooling of the building's cover can be performed through several techniques including the use of water and plants for horizontal surfaces. It can also find contemporary cooling methods for building surfaces which provide active movement of natural air currents within the building (known as the attic). It is suitable for ventilation of housing in temperate climates including also what is known as double ceilings and separated by an air space. Some of them have a light metal cover and a vacuum that is added to the ceiling of the building and the shadow of the building. Additionally, others have an air space connected with double spaces of walls and areas under the floor of the building as shown in Fig. 5 .

The role of solar breakers for reducing convection: It is well known that solar breakers can be either vertical or horizontal surfaces. Furthermore, it might be mounted either in portrait orientation or oblique direction on the façade. Moreover, it can be placed either on the edges of the window or in the front, so that, the window shade from the direct sunlight according to the horizontal angle and anchored to the Sun. Solar breakers can be considered as particular structural elements that have an impact on the protection of buildings from direct sunlight. It has the advantage of allowing low solar rays to enter the building during the period of high solar radiation during the Summer. This property is an essential tool in solar control, especially in hot areas. The primary function of the Sun breaker should provide the necessary protection from the direction of sunlight without blocking the vision and providing natural ventilation, in addition, its ability to reduce the amount of heat gained. There are many types of Sun breakers including horizontal Sun breakers, Sun-beams and Sun-blockers. The following explains the properties of both horizontal and vertical breakers:

- Horizontal breakers are useful when it is used to shade a window on the Southern facade where they prevent sunlight from entering the Summer

- Vertical breakers are also useful when it is implemented to shade a window on the North façade. In the case of the Eastern and Western façades it is possible to use moving head Sun catheters as they are more effective than fixed sunspots

The horizontal coupling union with the vertical (composite) can be used to shade a window on the South facade and utilized on the Eastern and Western interfaces in the case of making the vertical breakers moving and horizontally fixed (or vice versa) (Ali, 2011).

Elements of air flow rate calculation for ventilation and their types: Natural wind speed ventilation with equal openings for air entry and exit: there are several factors associated with securing natural ventilation by taking advantage of the speed and movement of air resulting from the force of the external wind. These factors are: 
mean wind speed, wind direction, daily and seasonal changes of wind speed and direction and the impact of adjacent buildings, highlands and other obstacles in wind movement (McQuiston and Parker, 1982). Air vents are preferred to be directly facing the direction of the external wind. Additionally, air exit vents on the opposite side or at the ceiling and at the low-pressure position of the ceiling or wall.

Natural ventilation resulting from air temperature difference inside and outside the building and the existence of feeding holes and ejections for this purpose: As a result of the temperature difference of the air with the outside, air flow occurs due to the difference of cold air density from the hot air. The hot air rises to the top and replaces cool air from outside the construction of the lower openings. The external air flow rate resulting from the temperature difference can be calculated according to the previous relationship.

Natural ventilation resulting from the combined effect of wind speed and temperature difference: when there is a combined effect of wind velocity and temperature difference it is not possible to collect the flows. In this case, the flow calculation is determined from the following relationship:

$$
\text { V.f }=V_{\text {total }}
$$

where, $f$ is the correction coefficient.

Experiment study: In order to achieve thermal comfort and provide natural ventilation within the spaces of public buildings, the building of the Faculty of Education at the University of Kirkuk was chosen for study and application of design elements. It is important for mentioning that the situation may change the reality of the state of the building from one case to another according to the surrounding climate and achieve thermal comfort through the application of special programs. The experiments were carried to calculate the changes in the event of altering or adding additional design elements to reach the desired goal.

Existing computer programs such as RIVET and DesignBuilder are used to calculate the required data. In the first step using RIVET, the architecture of the building was designed. Then, the design has transferred to the "DesignBuilder". After that, the required climate data has added in order to evaluate the results that represent the reality of the building. We then designed the solar breakers and inserted the wind catcher on the roofs. Accordingly, we recalculated the outcomes to achieve thermal comfort and natural ventilation in the interior spaces of the building (our study goals). In the following subsections, we explain the programs and how they implemented in the experiments.
RIVET program: It is a well-known production design software and considered as one of the Autodesk programs. RIVET uses building information modeling technology (Building Information Modelling) by designing a model that contains construction information of geographical location, cost, characteristics of used elements, manufacturing characteristics and other essential data. This model can be implemented in structural analysis, energy and lighting analysis and estimating quantities of construction material and total cost (Stine and Hansen, 2018). The program allows the user to create a 3D Model that comprises of building elements from foundations, floors, walls, windows and ceilings. Furthermore, the software has the possibility of converting the design to a 2D Model and the composition of projections, study and rendering. The most important feature of the REVIT program from other design programs is that the model designer is always updatable for any change to the basic drawing. Finally, the rest of the dependent models such as projections, sections, quantities of materials will change accordingly (Sarhan and Zouini, 2017).

Design builder software: It is a specialized software in the field of (Green BIM) which are used to simulate energy consumed in buildings. The program is able to provide the possibility of simulation work for the whole building or parts of the building depending on the building model (Building Model). Additionally, it can simulate the geographical location and weather data for any building. This program was carried out to calculate the amount of the entering light to the building and the consumed energy due to cooling and the heating and the ventilation in the building at any time of the year (Garg et al., 2017). The program can also perform the following: calculate the amount of entering light to the building and the heat generated before and after the addition of the solar mass. Additionally, the software can calculate the impact on the consumed energy by cooling. Evaluate the impact of inserting the wind catcher on the natural ventilation of the building and its effect on cooling energy due to cooling.

\section{Steps of the experiments}

Step 1: The building of selected as a study sample (represented by the Faculty of Education, University of Kirkuk) was drawn by the Autocad program. The study sample is an area of $5000 \mathrm{~m}^{2}$ of one floor approximately Fig. 6. As shown in Fig. 7 (which is designed by REVIT), the building consists of seven floors.

Step 2: As shown in Fig. 8, the file containing the building drawings has transferred to a program to calculate the 

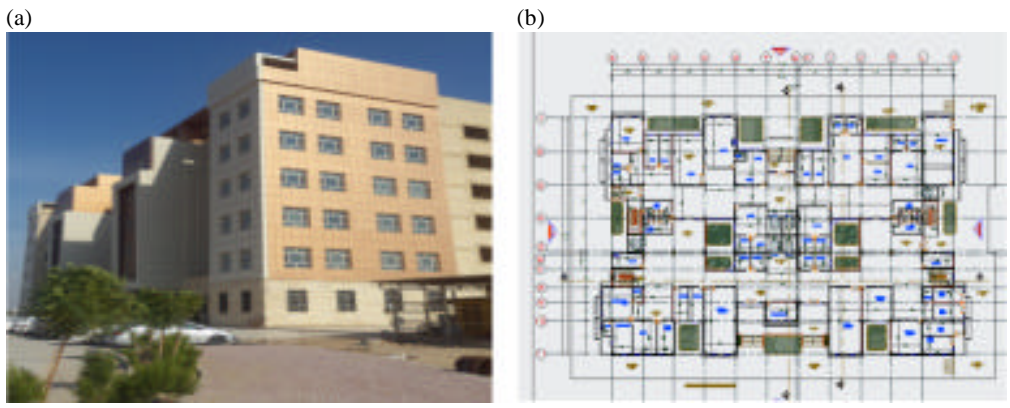

Fig. 6: a, b) Building College of Education University of Kirkuk (Photo researcher)

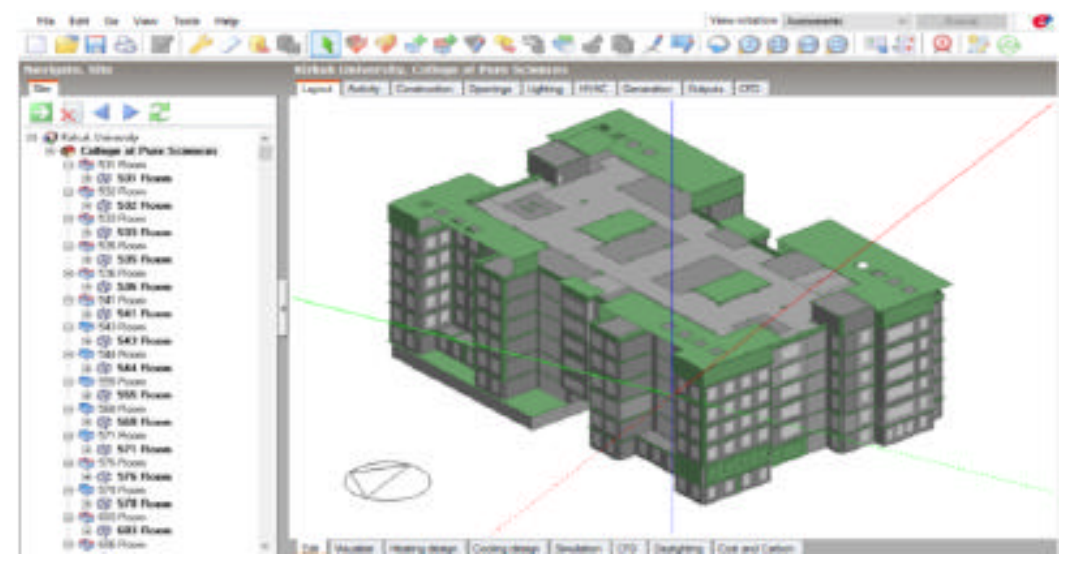

Fig. 7: Restructuring the building through the REVIT program

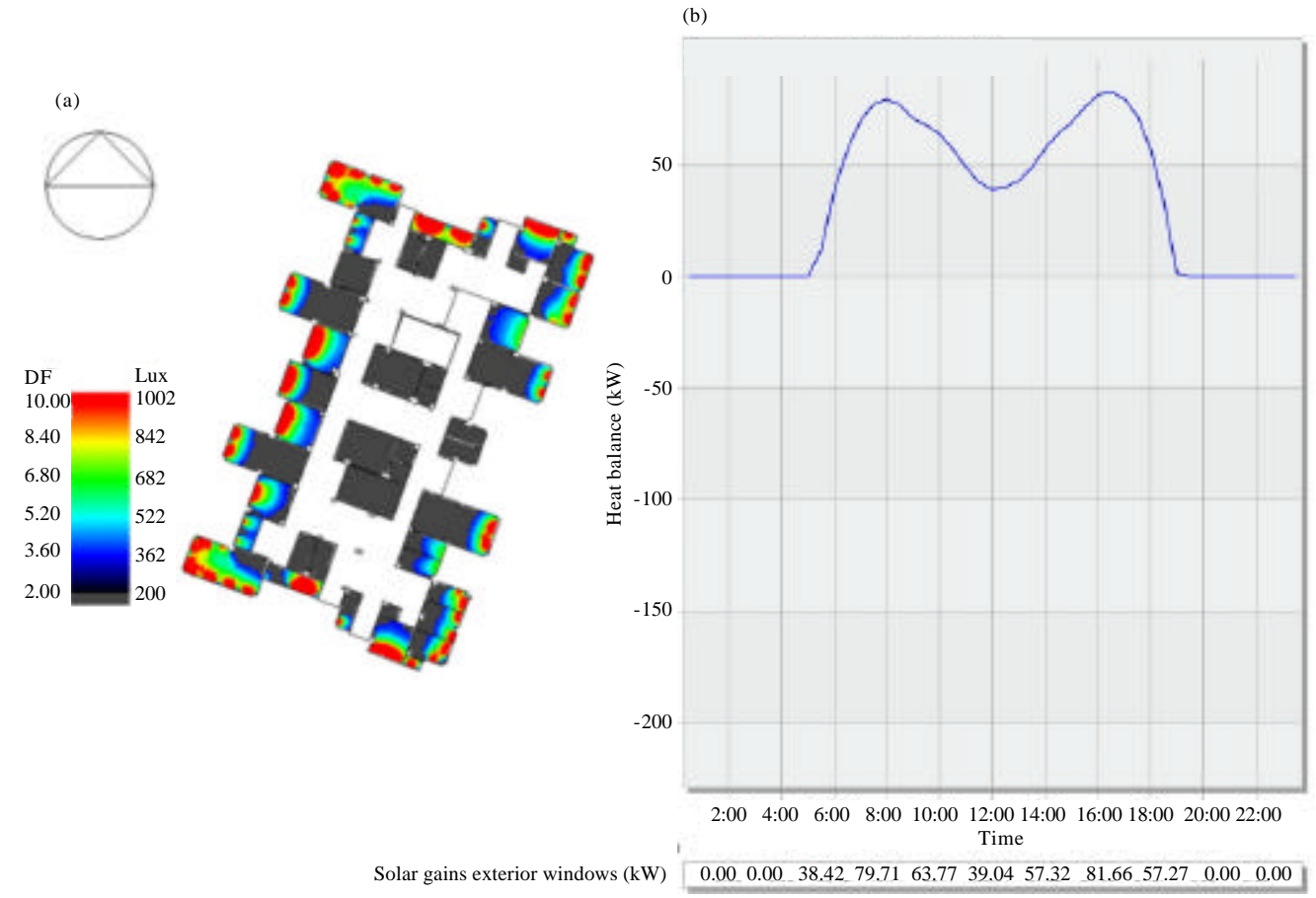

Fig. 8: a, b) The amount of bright light and the entering heat of the building before adding the proposed design elements; Temperature and heat gains-Kirkuk University 15 July, sub-hourly 
(a)

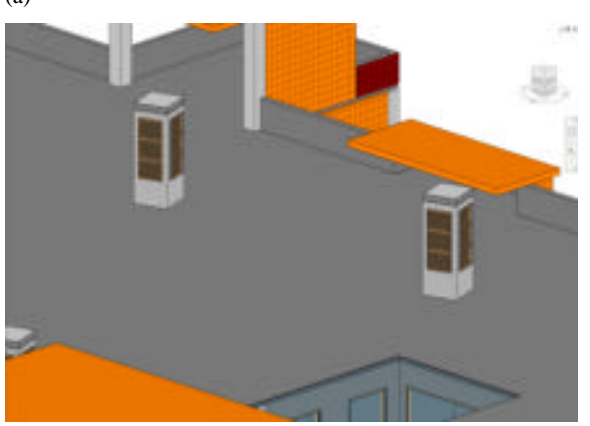

(c)

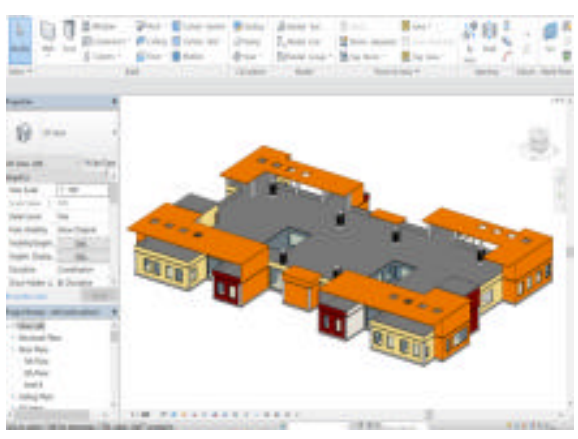

(e)

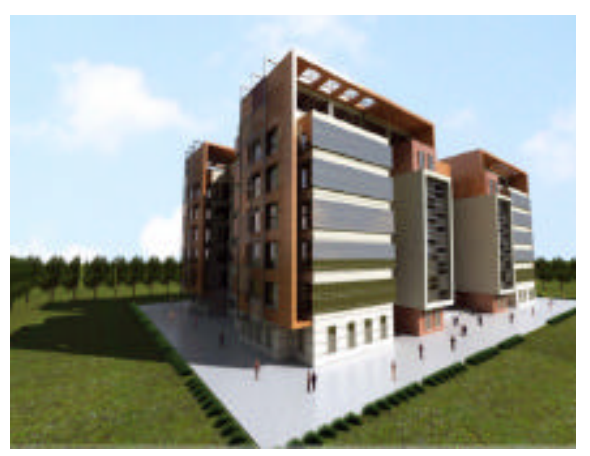

(b)

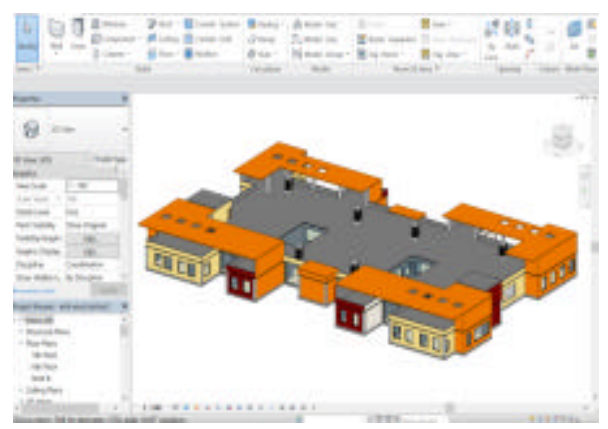

(d)

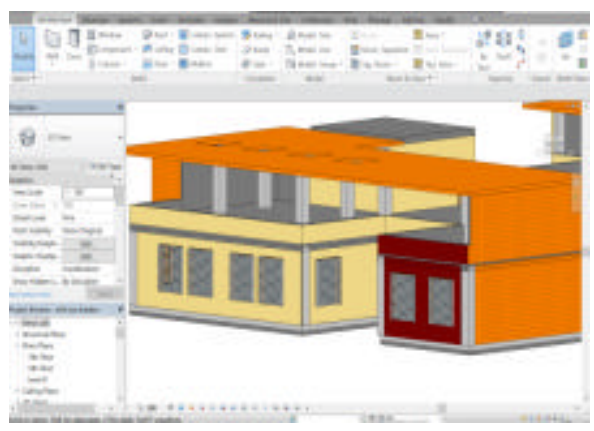

(f)

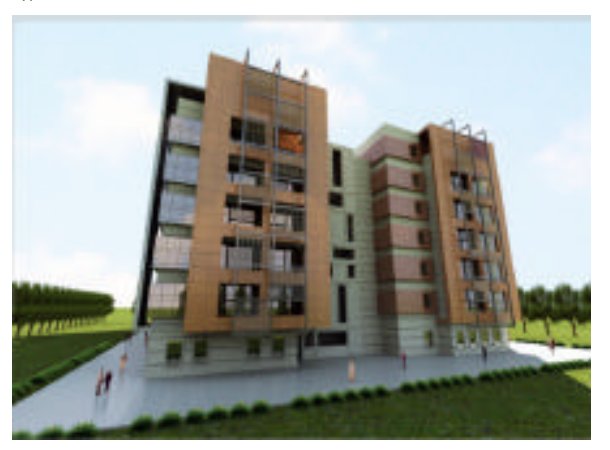

Fig. 9: a-f) The addition of new design elements (solar breakers, spacers and roofing)

convection degrees of the building's condition. According to climate information for the sample study area, the tangible results have achieved to meet the high rates of convection in the interior spaces of the building.

Step 3: A new design element was added to the building in order to reduce the convection and the direct bright light scattered inside the building spaces. It consists of olfactory fractures for exposed destinations to extend the periods of sunlight and direct perforation. In addition to this, air suspension was added which provide natural ventilation to a large proportion of the building's internal spaces through the exploitation of prevailing winds in the region. Figure 9 shows the inserted design elements to the study sample. As illustrated in Fig. 10 it is clear that the results were very positive as we found that the amount of convection is less than the quantity contained in the reality of the building. Furthermore, the amount of natural ventilation has also increased within the internal spaces of the building leading to achieve a healthy environment for the occupants of the building Fig. 11. Furthermore, through the positive results reached, we determined that the amount of energy spent has also decreased Fig. 12. Finally, the calculations were conducted for one floor where the results are multiplied by the number of floors of the building. 

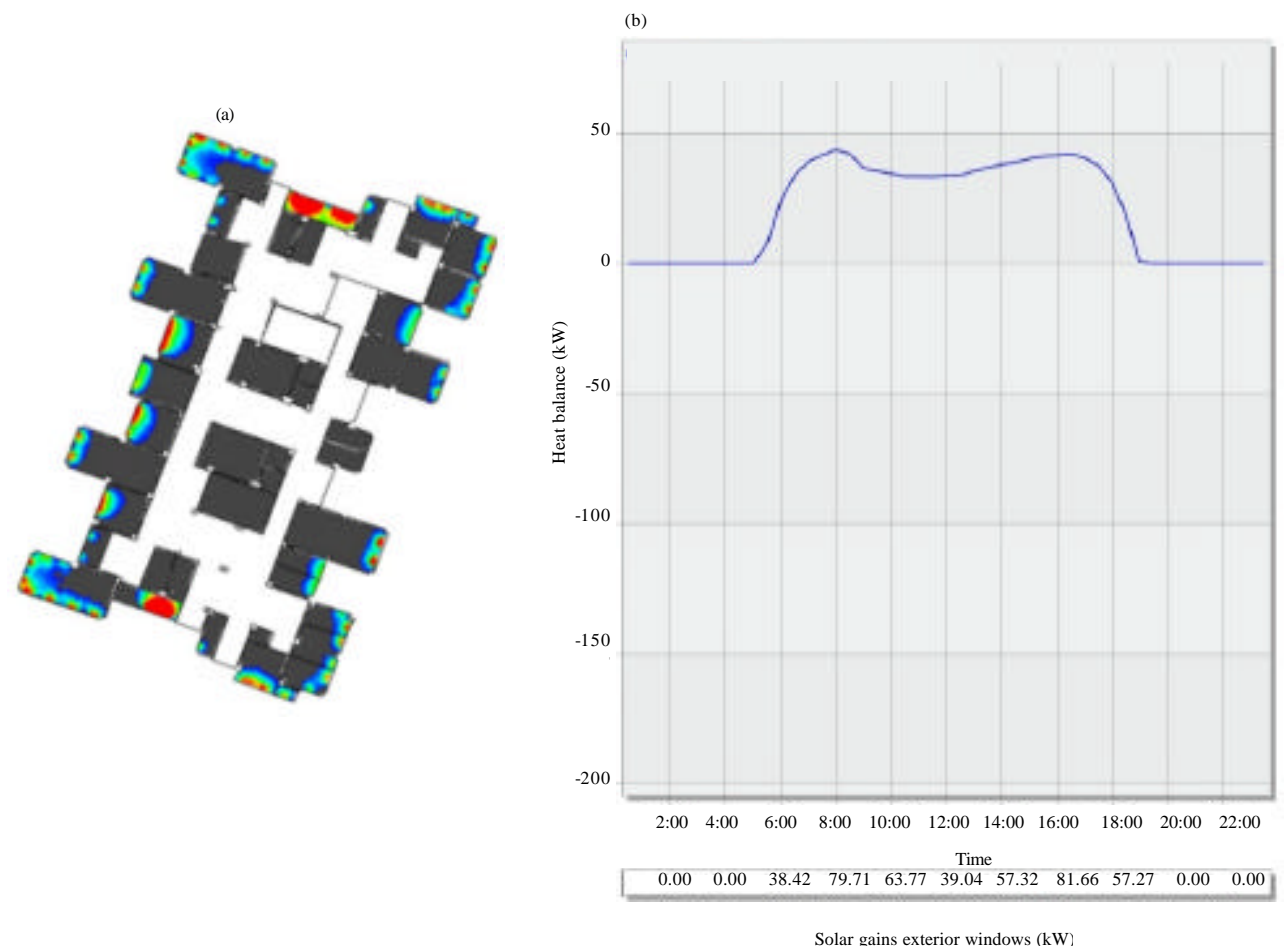

Fig. 10: The amount of convection after the addition of solar breakers and roof umbrellas: a, b) Temperature and heat gain-Kirkuk University 15 July, sub-hourly

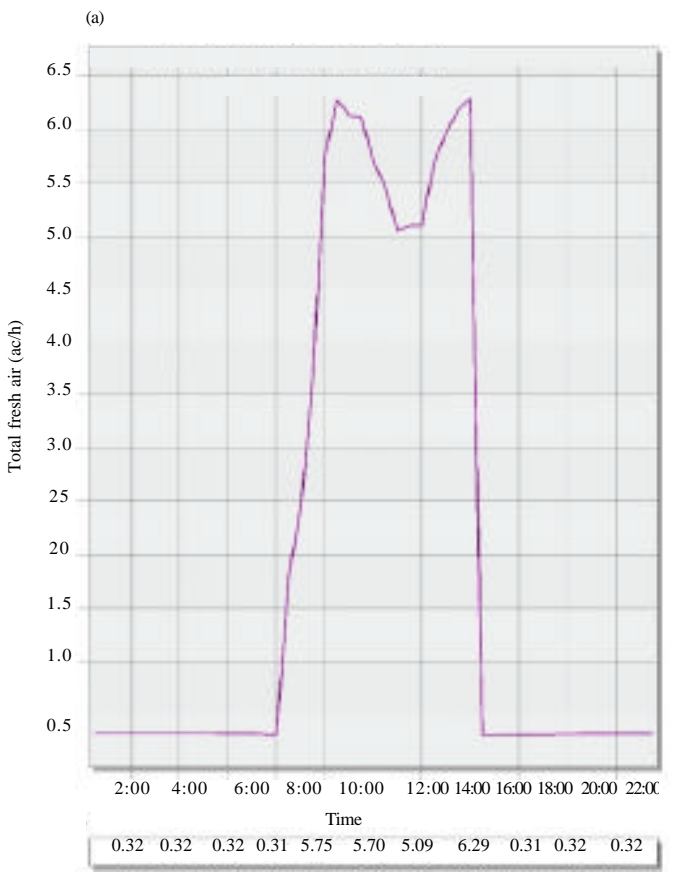

Mech Vent+Nat Vent+infiltration (ac/h)

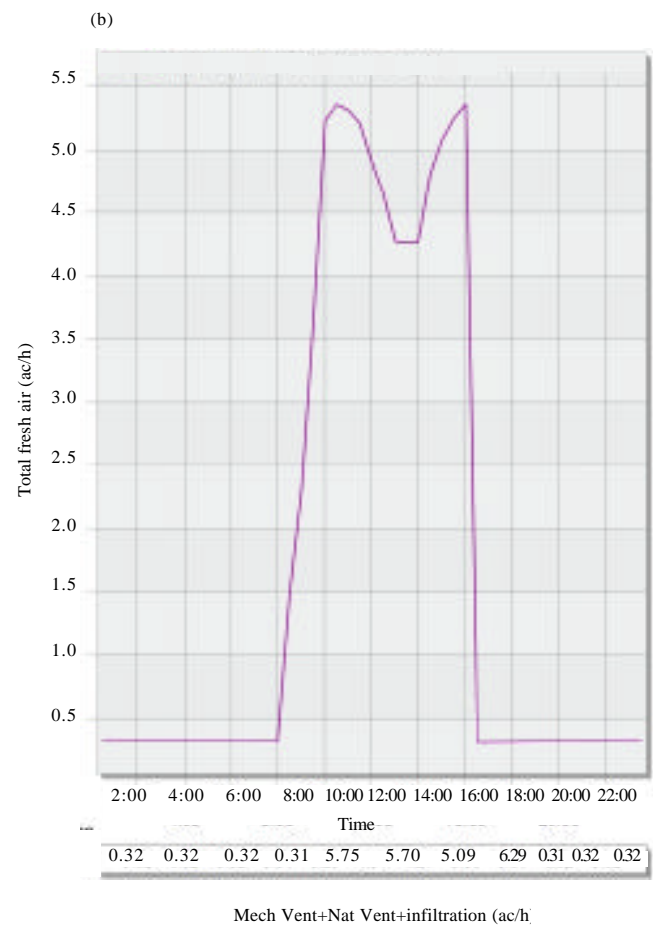

Fig. 11: The amount of natural ventilation that rises after the addition of the wind catcher: $a, b)$ Temperature and heat gains-Kirkuk University 15 July sub-hourly 
(a)

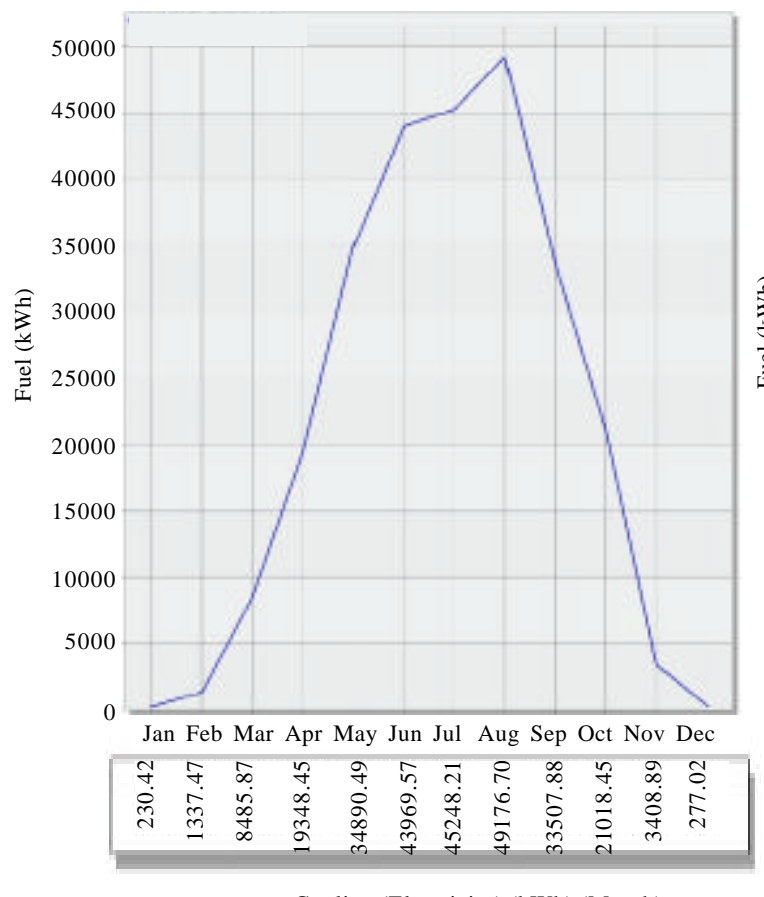

Cooling (Electricity) (kWh) (Month) (b)

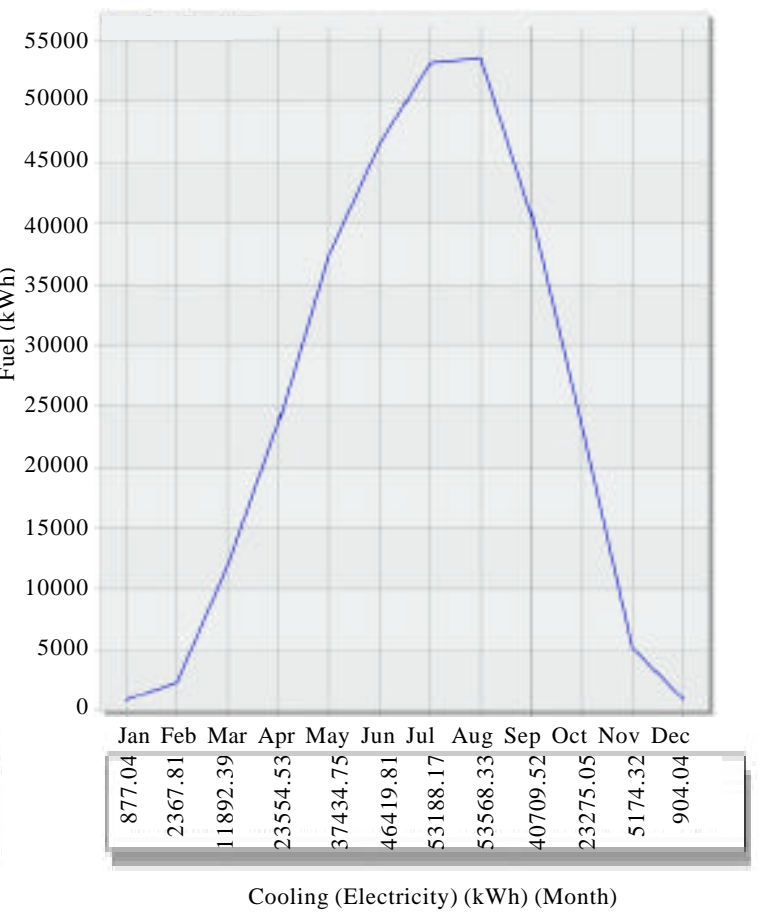

Fig. 12: The amount of electrical power spent per floor before and after the redesign: $a, b)$ Temperature heat gains and energy consumption-Kirkuk University 1 July, 31 December monthly

\section{RESULTS AND DISCUSSION}

From the above mentioned experiments, we summarize the findings as follows: it is vital to the use of simulation programs in the design of buildings to monitor the current situation and in searching for climatic solutions in conjunction with the architecture of the building. Thus, achieving the required thermal comfort in reality. It is essential to use natural cooling methods through the design methods to pull air into the spaces of buildings (such as wind catcher). Additionally, exploitation of the prevailing winds, especially, seasonal ones have a significant role in reducing the temperature. The benefit of using suitable solar breakers, especially, exposed facades to direct sunlight. Furthermore, it necessary that these solar breakers should be works to provide shadows, thus, providing thermal comfort for as long as possible within the spaces. The evolution of materials and methods of insulating the walls and roof of the building from solar radiation has helped to reduce the leakage of heat into the building's spaces. Despite the high cost of installing natural ventilation techniques it is economically viable in the long term. Reduces the cost of electrical energy significantly in case of adding the proposed design elements according to the results obtained through the simulation programs adopted.

\section{CONCLUSION}

Designers should be encouraged to rely on internationally approved software to conduct building simulations during design to minimize design problems that emerge after implementation. Furthermore, It is essential to take into account the technical development in designing elements that may lead to reduce the temperature in the interior spaces of public buildings.

\section{RECOMMENDATIONS}

It's necessity dependence on design principles that reduce mechanical means and directed towards the optimal exploitation of natural energy (such as the use of wind to provide natural ventilation). Finally, from the experiments, it is necessary to pay more attention to evolve software programs that can help the designers to test the design before implementation.

\section{REFERENCES}

Al-Hamdi, N.B.A.R., 1999. Thermal performance of buildings with soil in hot and dry climate in Saudi Arabia. King Saud Univ. J., 11: 23-50. 
Ali, A.M.M., 2011. Climate and desert architecture. Mod Prints, Noida, India.

Atkinson, J., ?Y. Chartier, ?C.L. Pessoa-Silva, P. Jensen and Y. Li et al., 2009. Natural Ventilation for Infection Control in Health-Care Settings. World Health Organization, Geneva, Switzerland, ISBN:9789241547857, Pages: 106.

Atwa, M.S., I. Mohieddin and M.M. Hajj, 2018. [Effect of using nanotechnologies and techniques in the outer casing on the quality of the internal environment in buildings (In Arabic)]. Baheth, 1: 1-19.

Auf, B.S.A.R.S., 1997. Climate Elements and Architectural Design. King Saud University, Riyadh, Saudi Arabia,.

Dragan, A., 2000. HVAC design approach and design criteria for health care facilities/Discussion. ASHRAE Trans., Vol. 106,

FP., 2019. Environmental engineering. Foster+Partners, London, England, UK. https://www. fosterandpartners.com/expertise/environmental-eng ineering/

Garg, V., J. Mathur, S. Tetali and A. Bhatia, 2017. Building Energy Simulation: A Workbook Using DesignBuilder ${ }^{\mathrm{TM}}$. CRC Press, Boca Raton, Florida, USA., ISBN:9781315351896, Pages: 464.
MLtd., 2019. The natural ventilation, daylight \& cooling specialists. Monodraught Ltd., Wycombe, England, UK.https:/www.monodraught.com/about-us/comp any-profile

McQuiston, F.C. and J.D. Parker, 1982. Heating, Ventilating and Air Conditioning: Analysis and Design. 2nd Edn., John Wiley \& Sons, New York, USA., ISBN:9780471082590, Pages: 666.

Riain, C.N., M. Kolokotroni, M. Davies, J. Fisher and M. White et al., 1999. Cooling effectiveness of South facade passive stacks in a naturally ventilated office building. Indoor Built Environ., 8: 309-321.

Sarhan, F.M. and I. Zouini, 2017. [Information Technology in Construction Project Management]. Dar Al-Manhal Publishers, Amman, Jordan, Pages: 213 (In Arabic).

Stine, D.J. and A.R. Hansen, 2018. Interior Design Using Autodesk Revit 2019. SDC Publications, Mission, Kansas, ISBN-13:978-1-63057-183-2, Pages: 66.

Waziri, Y., 2007. Environmentally-Friendly Architectural Design: Towards Green Architecture. Madbouly Library, Cairo, Egypt, 